\title{
PBL and LBL Combination Pedagogy in Teaching of Structural Mechanics
}

\author{
Xiaomei Shen \\ Civil Engineering \& Architecture college,JiaXing University, JiaXing, Zhejiang, China \\ Email: sxm2005hx@126.com
}

Keywords: structural mechanics; LBL pedagogy; PBL pedagogy; civil engineering

\begin{abstract}
Structural Mechanics is an important foundation course majoring in the civil engineering. The teaching methods of structural mechanics are of great significance for improving the teaching quality in the civil engineering. The problems of traditional pedagogy are discussed in allusion to the characteristics of structural mechanics with the requirements of the teaching objectives. In the meantime, the function of combined PBL and LBL pedagogy in the teaching course of structural mechanics is explored. The teaching practice has proved that the PBL and LBL pedagogy have their own strengths in the implementation of teaching process, only when both are fully integrated, can the effect be perfect.
\end{abstract}

\section{Introduction}

"Structural Mechanics" is playing a important role as a professional and foundational course in the major of civil engineering. The course provides the necessary basic knowledge and computing method not only for the subsequent courses, but also repeatedly used in the process of curriculum or graduate design with the knowledge of structural mechanics. Structural mechanics is a link between the core position throughout the curriculum system. Teaching methods refer to the technique used in order to meet the general term for teaching purposes and the way to complete the teaching task or teaching objectives. In many teaching methods, how to choose the better appropriate pedagogy requires the practice and experience. A variety of pedagogy are practiced in the teaching process. In order to achieve the goal of engineering applications and creative talents, Problem-Based Learning pedagogy which has widely been used in clinical medicine teaching is initially proposed to teaching reform of structural mechanics. First of all, the key points and difficult points are picked up to match the proper real-life cases. Students are guided to put themselves into the actual situation and to participate in the discussion and solution of problems. In this way, students can use their brain to think and share the ideas with all others. This is broadening the scope of mind with the enthusiasm stimulated at the same time. The theoretical knowledge is penetrated to engineering practice, which is easier for students to digest.

PBL pedagogy which has widely been used in clinical medicine teaching is initially proposed to teaching reform of structural mechanics. First of all, the key points and difficult points are picked up to match the proper real-life cases. Students are guided to put themselves into the actual situation and to participate in the discussion and solution of problems. In this way, students can use their brain to think and share the ideas with all others. This is broadening the scope of mind with the enthusiasm stimulated at the same time. The theoretical knowledge is penetrated to engineering practice, which is easier for students to digest.

\section{LBL pedagogy and PBL pedagogy}

Lecture-Based Learning pedagogy is also known as the traditional teaching mode. The features of LBL pedagogy are classroom-centered and teacher-dominant with teaching material presented[1]. It is performed by teachers through lectures, writing on the blackboard and auxiliary teaching media etc. to teach the content. Teachers are the main body in the whole process of teaching, but students are staying in the position of passive acceptance. The traditional teaching 
method being applied in the structural mechanics is in the greater inclination to examination. The normal way is that the teachers teach without students' participation during the whole class time. It will surely simplify the teaching process if irrelevant multi-media is made use for the class and make the students feel boring. Once the students missed one or two classes and did not keep up the pace with teaching, they probably give up. And the knowledge remembered is very easy to forget after exam.

One of the traits of LBL pedagogy is focusing on teaching foundational theoretical knowledge and helping students grasp them in detail. The advantage of the traditional teaching mode is that teachers can impart the knowledge to the students systematically and comprehensively. On the other hand, the traditional teaching method has shortcomings as well. It only pays attention to the mode and teaching content at the cost of ignoring students' feeling. It did not realize the beneficial combination of theory and practice to stimulate students' enthusiasm.

Problem-Based Learning pedagogy is pioneered by the American Academy of Neurology Professor Barrows, which has become a quite popular teaching method[2]. This way of teaching students breaks the traditional teacher-centered and lecture-based teaching model, emphasizing active learning[3]. PBL teaching method is characterized by PBL pedagogy with real and vivid circumstances. It promotes the initiative of students to participate in classroom teaching and activate the classroom atmosphere, which are conducive to improve teaching efficiency. Moreover, students can become of independent thinking ability and of much creativity. PBL teaching mode is shown as Figure 1.

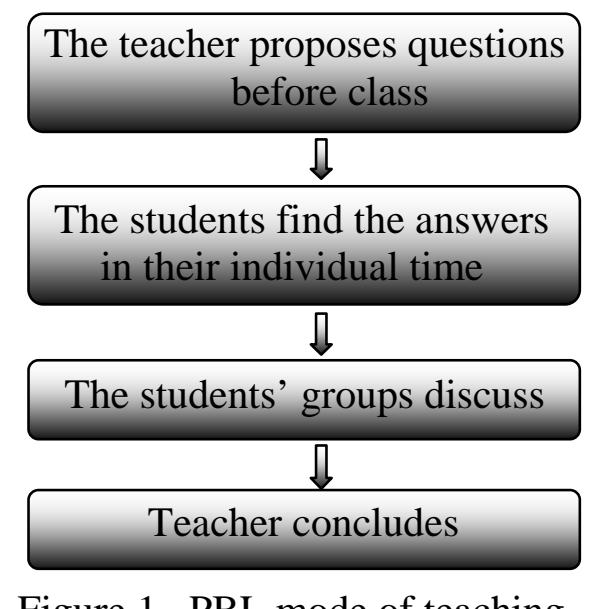

Figure 1. PBL mode of teaching

But there are also some problems using PBL, such as teaching content contained less than that of the traditional curriculum. Students have to focus on solving problems, while ignoring the learning objectives. Students' knowledge is very fragmented, and can not form the system. This will be far away from the level of mastery, detrimental to the future development of students. So for that, students only have the strong practical ability but poor theoretical knowledge.

By comparison, the conclusion is that PBL and LBL combination pedagogy can complete teaching objectives and tasks of structural mechanics.

\section{PBL pedagogy combined with LBL pedagogy}

LBL pedagogy is placing emphasis on the knowledge itself. It does not fully take into account the feelings of students. And it ignores to cultivate students' comprehensive quality and comprehensive ability. However, PBL pedagogy is just able to make up this defect. If only PBL pedagogy is used in the course of structural mechanics teaching, even if it improves the students' independent learning and problem-solving skills, but there is still a lack of systematic study of the theoretical knowledge, which is detrimental to the overall development of students. Therefore PBL pedagogy can not completely replace the traditional pedagogy. Teachers still need to wort out the key points and difficulties in the course system and represent students the systematic frame-based 
knowledge to deepen understanding and memory [4]. It's not unrealistic to rely on students' selflearning for solution of the difficult problems.

PBL and LBL pedagogy are highly complementary. Both are essential and neither was superior to the other, each with its own sphere of competence. They bring their own superiority into full play and overcome each other's shortcomings. This will be surely obtaining the satisfactory teaching effect. PBL and LBL combination pedagogy are applied into teaching practice and confirmed that it can really get a good teaching effect. The advantages of PBL teaching model and traditional LBL teaching model combined as a "two-trail" teaching model has become a real and necessary choice and process of teaching information. It keeps away from the limitation of partial knowledge or unsound foundation. At the same time, it can stimulate students' enthusiasm in studying. The research was done through the students involved, who advised that they really enjoyed this new teaching model. Moreover, they consider themselves as the host of learning, which is accelerating their own development. PBL and LBL combined mode of teaching is shown as Figure 2.

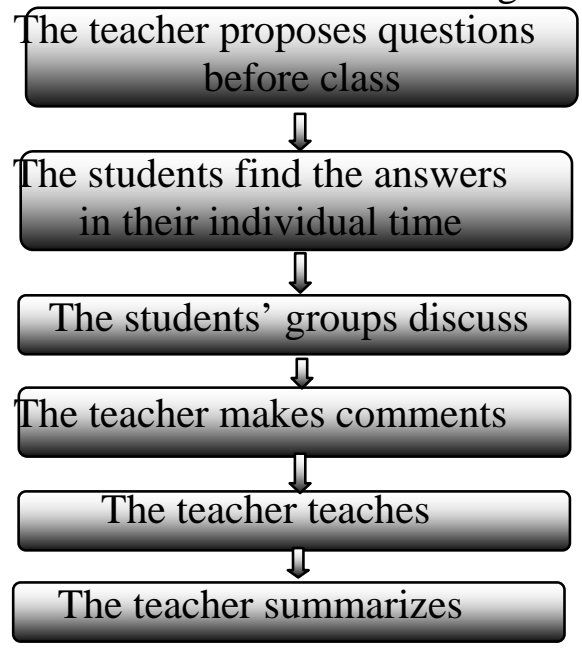

Figure 2. PBL and LBL combined mode of teaching

The author makes full use of a combination of PBL and LBL pedagogy with specific teaching process like as following. Firstly, the questions were assigned during students' individual studying time. And then what's the important is that the students were guided to look for as much information as possible no matter surfing the internet or going to the library. In the meantime, the teacher had to listen to the students' report in succession. At last but not the least, the teacher should give comments on each report specifically. The course ended with the teacher's teaching through multi-media based on LBL pedagogy.

\section{Issues that PBL pedagogy and LBL combination pedagogy should be paid attention}

The points being worth paying attention will be listed as below for reference[5-6].

1) The questions provided should be in the middle level. It helps to build students' confidence to learn. Too difficult questions should be left to teach in the classroom.

2) The teacher's comments play an important part of the implementary plan. A influential strict evaluation system should be established. And the evaluation introduced should take a certain proportion of the total score which won't be overlooked to motivate students' initiative studying.

3) Higher requirements are needed for teachers to improve their own quality and skills.

4) The evaluation for each group of students has to be consistent in order to urge the students to learn, but also to promote the unity and cooperation within the group.

5) It will be encouraging for the teacher to guide students to study in their own time including recommendation of the reference books.

6) The multimedia courseware for classroom teaching should be scientifically selected with the suitable teaching content.

7) The teacher should be involved throughout the implementation process, but participation should just play the role of supervision and guidance, by all means avoid to be the host or the 
leader. .

8) The teacher needs to take their spare time to collect cases prior to class. As well, the reasonable scientific progressive interlocking problems will be a superiority.

All above achieved is being defined as a success of PBL and LBL teaching mode.

\section{Conclusion}

Along with the continuous development of teaching goals, the quality education is being popularized incessantly. Undoubtedly higher requirement is a must for teaching. Students are being appointed to have strong logical, analytical, innovative and organizing ability besides the rich theoretical knowledge. So for that, teachers have to go for a suitable pedagogy at times to adapt to the new requirements and constantly to improve the teaching quality to enhance students' comprehensive quality. So traditional teaching methods are difficult to meet the requirement. Teaching practice proved that combined PBL and LBL teaching mode is an efficient pedagogy, which is perfectly suitable for the teaching of structural mechanics. It is a new way to cultivate more comprehensive quality talent, that should be widely applied and further studied.

\section{References}

[1] WeishengYang. The teaching method reform of human anatomy.China Medical Herald, 2010,7(28):115-116.

[2] Tavakol. K eicherter. E. A. The role of problem-based learning in theenhancement of allied health education. J Allied Health, 2003,32(2):93-96.

[3] Dolmans DH, De Grave W, Wolfhagen IH, et al. Problem-Based Learning :Future Challenges for Educational Practice and Research. Med Edu, 2005,39(7):732-741.

[4] Thomas H Davis, Galen S Wagner, Gilbert Gleim, et a1 .Problem-based learning of research skills. Journal of Electrocardiology, 2006,39(1):120.

[5] Ebstein RJ. Learning form the problems of problem based learning. BMC Med Educ 2004; 4:1-7.

[6] Yuxian Li, Bao Zhang. Introduction to the traditional teaching method and PBL teaching method in the integrated applications. Chinese Medicine Modern Distance Education of China,2011,9(5):74-75. 